\title{
A new melatonin oral delivery platform based on orodispersible films containing solid lipid microparticles.
}

Umberto M. Musazzi ${ }^{1}$, Luisa S. Dolci ${ }^{2}$, Beatrice Albertini ${ }^{2}$, Nadia Passerini ${ }^{2}, *$, Francesco Cilurzo ${ }^{1}$

${ }^{1}$ Department of Pharmaceutical Sciences, Università degli Studi di Milano, Via G. Colombo 71, 20133 Milano, Italy

${ }^{2}$ Department of Pharmacy and BioTechnology, University of Bologna, Via S. Donato 19/2, 40127 Bologna, Italy

*corresponding author

Prof. Nadia Passerini

Department of Pharmacy and BioTechnology,

University of Bologna,

Via S. Donato 19/2, 40127 Bologna, Italy

Phone $+39-0512095613$

nadia.passerini@unibo.it 


\begin{abstract}
:
An innovative delivery system for melatonin, based on the incorporation of solid lipid microparticles in orodispersible films (ODFs) made of maltodextrin, was designed and developed. Lipid microparticles at two different melatonin concentrations (10 and $20 \% \mathrm{w} / \mathrm{w}$ ) were produced by the spray congealing technology using two different lipid carrier (tristearin and hydrogenated castor oil) and characterized in terms of size, solid state, drug loading and drug release pattern. Tristearin microparticles were discarded due to a polymorphic modification of the carrier. The incorporation of hydrogenated castor oil microparticles in ODFs by using the casting method did not alter significantly the shape and dimension of the microparticles and the mechanical properties (elasticity and strength) of the films, which remained acceptable for manufacturing and handling. The in vitro release studies performed in saliva, gastric and intestinal simulated media on ODFs containing melatonin loaded in hydrogenated castor oil microaparticles revealed the possibility to combine with an immediate release of the drug and a sustained release over at least $5 \mathrm{~h}$ period.

In conclusion, the proposed drug delivery system maintains the advantages of ODFs, i.e. the suitability to be swallowed without water, and permits the tuning of drug release according to the clinical needs by modulating the ratio of free and microencapsulated drug in the ODF.
\end{abstract}

\title{
Keywords:
}

Melatonin; maltodextrins; spray congealing; orally disintegrating films; personalized medicine, modified drug release. 


\section{Introduction}

Melatonin, an indoleamine secreted by the pineal gland during the night, plays a key role in regulating circadian rhythm. The administration of this neurohormone is useful for the treatment of sleep disorders in both elderly ${ }^{1}$ and children. ${ }^{2,3,4}$ Melatonin is available on the market as immediate release dosage form or modified release tablet (Circadin ${ }^{\circledR}$ ). In the former case, the maximum plasma concentration is reached within $60 \mathrm{~min},{ }^{5}$ then it undergoes hepatic metabolism and the $80-90 \%$ is converted to 6-sulphatoxymelatonin, an inactive compound excreted in the urine. In Europe, the Circadin ${ }^{\circledR}$ is available on the market as a medicinal product containing 2 mg of melatonin in the form of prolonged release tablets and it is approved for the treatment of primary insomnia in patients aged 55 years and older. ${ }^{6}$ The release profile from the modified release tablet exhibits an initially fast release (approximately a third of the dose in the first hour) followed by a slower prolonged release with the aim of promoting the induction and maintenance of sleep. Despite the relative small tablet dimensions of Circadin $^{\circledR}$, some patients (elderly, disabled or children) have difficulty swallowing the formulation intact and may require tablets to be divided or crushed to ease administration, thus producing the loss of the prolonged-release properties and the alteration of its clinical effect. ${ }^{7}$ Thus, new dosage forms such as solid lipid microparticles to be dispensed in sachets ${ }^{8}$ and hydrophilic matrix tablets based on cyclodextrins ${ }^{9}$ have been proposed.

An alternative approach to fulfill all the requirements reported above, namely the fast onset of action combined with a prolonged release and easiness of swallowing, could reside in the development of orodispersible dosage forms that disintegrate and/or dissolve rapidly upon contact with saliva after being placed on the tongue and, as a consequence, permit patient to not swallow the intact solid dosage form, but as drug solution/suspension in saliva fluids. ${ }^{10}$ Among such dosage forms, orodispersible films (ODFs) appear particularly attractive since they avoid the fear of chocking, that still remains in the orodispersible tablets. ${ }^{11}$ Moreover, they are well accepted by paediatric patients and their caregivers (e.g., family members or nurse). ${ }^{12,13}$ However, conventional ODFs are immediate release dosage forms, thus they are not able to modulate the release of the loaded drug. An innovative and very interesting strategy to solve this issue, which could be useful for the development of a melatonin delivery systems, is the loading in the ODFs of a microencapsulated drug. Recently two papers published by the Breitkreutz research group at the Heinrich Heine University suggested that the incorporation of drug-loaded polymeric microparticles produced by hot-melt extrusion ${ }^{14}$ or by wet extrusion and spheronizzation ${ }^{15}$ into ODFs provided prolonged drug release properties. However, the selection of polymers to be used 
in the design of microparticles is particularly critical due the possible interactions with glycerine or propylene glycol, which are the plasticizers most used to tune-up ODFs tensile properties. A possible alternative to the use of polymeric microparticle to achieve a prolonged release is represented by solid lipid microparticles, due to the favourable biocompatibility and lower toxicity of the lipids compared with many polymers ${ }^{16,17}$ and the lack of significant interaction with hydrophilic plasticizers commonly used in the design of ODFs.

The aim of this study was to investigate the feasibility of innovative ODFs as delivery system for melatonin able to either decrease the sleep onset latency and to increase the total sleep time, suitable for patients with swallowing difficulties such as children and the elderly. In the attempt to guarantee both a fast onset of action and a prolonged release, different ODFs formulations, containing melatonin-loaded lipid microparticles and/or the free dispersed drug, were studied. For the design of the ODF maltodextrins were selected since their use as well as the possible impact of formulative variables on film mechanical properties are well known. ${ }^{18}, 19,20$

\section{Materials and methods}

\subsection{Materials}

Maltodextrins having a dextrose equivalent (D.E.) equal to 6 (Glucidex ${ }^{\circledR}$ IT6) were kindly obtained by Roquette (Lestrem, France). Glycerin (GLY), Span ${ }^{\circledR} 80$ (S80) and Tween ${ }^{\circledR} 80$ (T80) were purchased from Carlo Erba Reagenti (Milan, Italy) and Croda (Snaith, UK), respectively. Melatonin (MLT) was purchased from Farmalabor (Assago, Italy). MLT was milled and sieved; the fraction lower than $50 \mu \mathrm{m}$ was used. Tristearin (Dynasan 118) and hydrogenated castor oil (Cutina HR) were a gift from Sasol (Witten, Germany) and Gattefossè Italy (Milan, Italy), respectively. All solvents were of analytic grade, unless specified.

For the dissolution studies, the following media were prepared: 1) Simulated Salivary Fluid: $1 \mathrm{~L}$ contained $2.38 \mathrm{~g} \mathrm{Na}_{2} \mathrm{HPO}_{4}, 0.19 \mathrm{~g} \mathrm{KH}_{2} \mathrm{PO}_{4}$ and $8 \mathrm{~g} \mathrm{NaCl}$, the $\mathrm{pH}$ was adjusted at 6.8 using phosphoric acid $\left(\mathrm{H}_{3} \mathrm{PO}_{4}\right) ; 2$ ) Simulated Gastric fluid: $2.92 \mathrm{~g}$ of $\mathrm{NaCl}$ and $7.04 \mathrm{~mL}$ of hydrochloric acid were dissolved in deionized water up to $1 \mathrm{~L}$., finally the $\mathrm{pH}$ was adjusted to 1.2 ; 3) Simulated intestinal Fluid: $6.8 \mathrm{~g}$ of potassium dihydrogen phosphate and $0.9 \mathrm{~g}$ of sodium hydroxide were dissolved in deionized water to obtain a total volume of $1 \mathrm{~L}$ and the $\mathrm{pH}$ was adjusted to 6.8 . 


\subsection{Preparation of the solid lipid microparticles}

For the microparticles (MP) production two different excipients, namely hydrogenated castor oil (Cutina HR, melting point $85-90^{\circ} \mathrm{C}$ ) and tristearin (Dynasan 118 , melting point $75-80{ }^{\circ} \mathrm{C}$ ) were used. The MPs were produced by the spray congealing process using the wide pneumatic nozzle (WPN) already described in detail in our previous work ${ }^{8}$. Both placebo MP and MLT-loaded MP at two different concentrations (10 and $20 \% \mathrm{w} / \mathrm{w}$ ) were produced (Table 1). The excipient was melted in a water bath kept at $10^{\circ} \mathrm{C}$ above the melting point of the excipient. For the preparation of MLT loaded microparticles, melatonin was added to the molten excipient in two different concentrations and stirred for 15 minutes in order to obtain a homogeneous suspension, which was then loaded into the feeding chamber of the WPN. WPN parameters were set at a temperature of $80^{\circ} \mathrm{C}$ for tristearin and $95{ }^{\circ} \mathrm{C}$ for hydrogenated castor oil with an air pressure of 4 bar.

Microparticles were collected, sieved using a vibrating shaker (Octagon Digital, Endecotts, London, UK) to select the fraction between 50 and $75 \mu \mathrm{m}$ sieves (useful fraction), and stored in polyethylene closed bottles at $4 \pm 2^{\circ} \mathrm{C}$.

Table 1 - microparticle composition, yield and melatonin (MLT) content

\begin{tabular}{ccccc}
\hline Form. & Material & $\begin{array}{c}\text { Nominal MLT } \\
\text { content }(\% \mathbf{w} / \mathbf{w})\end{array}$ & $\begin{array}{c}\text { Actual } \mathbf{M L T} \\
\text { content }(\% \mathbf{w} / \mathbf{w})\end{array}$ & $\begin{array}{c}\text { Useful } \\
\text { yield }\end{array}$ \\
\hline $\mathrm{MP}_{1}$ & tristearin & 0 & - & - \\
$\mathrm{MP}_{2}$ & tristearin & 10 & $8.6 \pm 0.1$ & $42.3 \%$ \\
$\mathrm{MP}_{3}$ & tristearin & 20 & $16.0 \pm 0.4$ & $37.5 \%$ \\
$\mathrm{MP}_{4}$ & $\begin{array}{c}\text { hydrogenated } \\
\text { castor oil }\end{array}$ & 0 & - & - \\
$\mathrm{MP}_{5}$ & $\begin{array}{c}\text { hydrogenated } \\
\text { castor oil } \\
\text { hydrogenated } \\
\text { castor oil }\end{array}$ & 10 & $8.1 \pm 0.1$ & $28.8 \%$ \\
$\mathrm{MP}_{6}$ & 20 & $17.0 \pm 0.1$ & $23.8 \%$ \\
& & & & \\
\hline
\end{tabular}

\subsection{Characterization of the solid lipid microparticles (MP)}

The useful yield was calculated from the mass of a useful fraction (50-75 $\mu \mathrm{m})$ by dividing it by the mass of the starting material (\% $w / w)$. 
Differential scanning calorimetry (DSC) measurements were performed using a PerkinElmer DSC 6 (PerkinElmer, Beaconsfield, UK) using nitrogen $(20 \mathrm{~mL} / \mathrm{min})$ as purge gas. The samples, weighing 8-12 mg, were placed into a non-hermetically aluminum pan and heated from $25^{\circ} \mathrm{C}$ to $150{ }^{\circ} \mathrm{C}$ at a scanning rate of $10^{\circ} \mathrm{C} / \mathrm{min}$.

Hot-stage microscopy (HSM) was carried out on hot stage apparatus (Mettler-Toledo S.p.A.) mounted on Nikon Eclipse E400 optical microscope connected to a Nikon Digital Net Camera DN100 for the image acquisition. The samples were heated at $25^{\circ} \mathrm{C}$ for $1 \mathrm{~min}$ for equilibration and then heated from $25^{\circ} \mathrm{C}$ to $130^{\circ} \mathrm{C}$ at a scanning rate of $10^{\circ} \mathrm{C} / \mathrm{min}$.

The actual amount of melatonin loaded into the MP was assayed spectrophotometrically (UV-vis spectrophotometer mod. UV2, Unicam, Cambridge, UK) at $277 \mathrm{~nm}$. Calibration solutions were diluted from the standard stock solution $(2 \mathrm{mg} / \mathrm{mL})$, in the concentration range of $0.5-40 \mu \mathrm{g} / \mathrm{mL}$. The calibration curves were assessed in both standard solution $\mathrm{pH} 1.5$ and 6.8. Each measurement was performed in triplicate and expresses as the mean \pm SD was reported. The correlation coefficient $\left(R^{2}\right)$ was equal to 1 in both standard solutions. For the drug content, about 20 or $30 \mathrm{mg}$ of MPs, according to the formulation, were accurately weighted and dispersed into $10 \mathrm{~mL}$ of opportune solution medium. The solution was heated at $10^{\circ} \mathrm{C}$ above the excipient melting point and gently shaken for $60 \mathrm{~min}$. Finally, the samples were cooled to room temperature, filtered, appropriately diluted and assayed. Each formulation was analyzed in triplicate in both media and the results were expressed as the mean \pm standard deviation (SD).

\subsection{Preparation of orodispersible films (ODFs)}

ODFs were prepared by the solvent casting technique as previously described. ${ }^{18}$ Briefly, Tween ${ }^{\circledast} 80$ and melatonin were directly added to the maltodextrin solution under constant stirring. In parallel, Span ${ }^{\circledR} 80$ was mixed with glycerin and, then, added to the Tween ${ }^{\circledR} 80 /$ melatonin mixture. After 30 min of mixing, microparticles were added gradually and the resulting dispersion was left to rest for removing bubbles. The dispersion was cast at the rate $1 \mathrm{~m} / \mathrm{min}$ over a silicone release liner and a coating thickness of the wet mixture was set $(250-350 \mu \mathrm{m})$ to obtain ODFs with a final thickness of 100-200 $\mu \mathrm{m}$ (Labcoater LTE-S(M), Mathis, CH). The dispersion was, then, dried in the machinery oven at $60^{\circ} \mathrm{C}$ for $12 \mathrm{~min}$, setting the circulation speed at $1800 \mathrm{rpm}$. The obtained ODF was cut into the shape and size required for testing, packed in individual airtight seal packs using a 
triple layer film, and stored at $25 \pm 1{ }^{\circ} \mathrm{C}$ until use. The composition of the prepared films is reported in Table 2.

Table 2 - Composition of ODFs loaded with free melatonin (MLT) and/or microparticles (MP).

\begin{tabular}{|c|c|c|c|c|c|c|c|}
\hline \multirow[b]{2}{*}{ Form. } & \multicolumn{6}{|c|}{ Composition $(\%, w / w)$} & \multirow{2}{*}{$\begin{array}{c}\text { Total MLT } \\
\text { content } \\
(\%, w / w)\end{array}$} \\
\hline & Maltodextrin & Span80 & Tween80 & Glycerin & $M L T$ & $M P$ & \\
\hline $\mathrm{F}_{1}$ & 80.30 & 0.78 & 1.55 & 17.37 & - & - & - \\
\hline $\mathrm{F}_{2}$ & 78.29 & 0.76 & 1.51 & 16.94 & 2.50 & - & 2.50 \\
\hline $\mathrm{F}_{3}$ & 75.45 & 0.73 & 1.46 & 16.33 & 6.03 & - & 6.03 \\
\hline $\mathrm{F}_{4}$ & 74.80 & 0.72 & 1.45 & 16.18 & - & $6.85^{1}$ & - \\
\hline $\mathrm{F}_{5}$ & 56.09 & 0.54 & 1.08 & 12.13 & - & $30.16^{1}$ & - \\
\hline $\mathrm{F}_{6}$ & 56.09 & 0.54 & 1.08 & 12.13 & - & $30.16^{2}$ & 2.50 \\
\hline $\mathrm{F}_{7}$ & 56.09 & 0.54 & 1.08 & 12.13 & - & $30.16^{3}$ & 5.69 \\
\hline $\mathrm{F}_{8}$ & 54.67 & 0.53 & 1.06 & 11.83 & 2.50 & $29.41^{2}$ & 5.00 \\
\hline $\mathrm{F}_{9}$ & 52.90 & 0.51 & 1.02 & 11.44 & 5.69 & $28.44^{3}$ & 11.38 \\
\hline
\end{tabular}

\subsection{Characterization of the ODFs}

The overall morphology of the ODFs were evaluated by Scanning Electron Microscopy (SEM). Samples were fixed on the sample holder with double-sided adhesive tape, sputter coated with $\mathrm{Au} / \mathrm{Pd}$ under argon atmosphere performed using a vacuum evaporator (Edwards, Crawley UK) and examined using a ESEM Quanta 200 (Fei Company - Oxford Instruments) operating at $30.0 \mathrm{kV}$ accelerating voltage. Three different magnifications (250X, 1000X and 5000X) were used.

The film thickness was measured in ten different positions by using a MI 1000 (Chemlnstruments, USA). The accuracy of the instrument was $2.5 \mu \mathrm{m} \pm 0.5 \%$.

Tensile properties of ODFs loaded with free and microencapsulated drug were determined by an Instron 5965 texture analyzer (Instron, UK), equipped with a $10 \mathrm{~N}$ load cell. In order to determine the influence of microparticles loading on the mechanical properties of ODFs, the tests were performed using formulations reported in Table 2 with the high microparticle concentrations (i.e., F6, F8, F9). The films were cut into $80 \times 12 \mathrm{~mm}$ strips and were equilibrated at $25 \pm 1{ }^{\circ} \mathrm{C}$ for 1 weeks. 
Each test strip was placed longitudinally in the tensile grips on the texture analyzer. Initial gap between the grips and crosshead speed were $40 \mathrm{~mm}$ and $12.5 \mathrm{~mm} / \mathrm{min}$, respectively. A preload was performed in each analysis. The test was considered concluded at the film break. The following parameters were determined: (i) Tensile strength $(\sigma)$ was calculated by dividing the maximum load by the original cross-sectional area of the specimen and it was expressed in force per unit area (MPa). (ii) Percent elongation at break ( $\varepsilon$ ) was calculated according to Eq. (1):

$\varepsilon=\frac{L-L_{0}}{L_{0}} \times 100$

where $L_{O}$ is the initial gage length of the specimen and $L$ is the length at the rupture. (iii) Elastic modulus or Young's modulus $(\mathbf{Y})$ was calculated as the slope of the linear portion of the stress- $\varepsilon$ curve. The result was expressed in force per unit area (MPa). (iv) Tensile energy to break (TEB) was defined by the area under the stress-strain curve. The results were expressed in MPa. An average of five measurements was taken for each type of specimen.

The particle distribution of microparticles before and after being loaded in the film was determined using an Accusizer ${ }^{\mathrm{TM}} 780$ Optical Particle size (PSS Nicomp, US). The MPs were suspended into a $0.01 \% \mathrm{w} / \mathrm{v}$ Tween ${ }^{\circledR} 80$ aqueous solution $(2 \mathrm{~mL})$. The surfactant was added to prevent microparticle aggregation. The analyses on microparticle loaded films were performed dissolving a film sample $\left(1 \mathrm{~cm}^{2}\right)$ in $2 \mathrm{~mL}$ of $0.01 \% \mathrm{w} / \mathrm{v}$ Tween ${ }^{\circledR} 80$ aqueous solution. Particle size distribution was expressed as undersize cumulative percentages of the area distribution. The population dispersity was referred as span, which was calculated according to the Eq. 2:

span $=\frac{d_{90}-d_{10}}{d_{50}}$

where $d_{90}, d_{50}, d_{10}$ are the mean diameter at the $90 \%, 50 \%, 10 \%$ of the population distribution respectively.

The ODFs were also characterized by mean DSC according to the method described above. The melatonin content was assayed using the same protocol used for microparticles. About 20 or $30 \mathrm{mg}$ of ODFs, according to the ODF formulation, were accurately weighted and dispersed into 10 $\mathrm{mL}$ of $\mathrm{pH} 6.8$ buffer. The solutions were heated at $90^{\circ} \mathrm{C}$ and gently shaken for $60 \mathrm{~min}$. Finally, the samples were filtered, cooled to room temperature, appropriately diluted and spectrophotometrically assayed. Each formulation was analyzed in triplicate and the results were expressed as the mean \pm standard deviation (SD). 


\subsection{In vitro release studies of melatonin from microparticles and ODFs}

In vitro release studies were carried out using a USP II apparatus (Erweka DT $800 \mathrm{GmbH}$, Heusenstamm, Germany) with a paddle rotation at $50 \mathrm{rpm}$. The temperature was set at $37 \pm 0.5^{\circ} \mathrm{C}$. The dissolution test of microparticles and ODFs was performed using $500 \mathrm{~mL}$ of a single dissolution medium (simulated salivary fluid or simulated gastric fluid at $\mathrm{pH} 1.2$ or simulated intestinal fluid at pH 6.8) for 60 minutes.

In addition, the release tests of ODF containing free drug and/or melatonin loaded microparticles were carried out by changing the $\mathrm{pH}$ of the dissolution medium: the ODF was first dissolved in simulated salivary fluid $(5 \mathrm{~mL})$ for 5 minutes, then this dispersion was transferred into $500 \mathrm{~mL}$ of simulated gastric fluid ( $\mathrm{pH} \mathrm{1.2)} \mathrm{for} \mathrm{one} \mathrm{hour} \mathrm{and,} \mathrm{finally,} 250 \mathrm{~mL}$ of a basic solution to obtain a final solution at $\mathrm{pH} 6.8$ to simulate the intestinal environment was added (simulated intestinal fluid). Overall the release experiments ran over a period of $5 \mathrm{~h}$.

Using both procedures, the medium was then the filtered through a $0.40 \mu \mathrm{m}$ poroplast ${ }^{\circledR}$ filter and continuously pumped $(12.5 \mathrm{~mL} / \mathrm{min}$ ) to a flow cell in a spectrophotometer (UV2 Spectrometer, Unicam, Cambridge, UK). The amount of melatonin dissolved was analysed at $277 \mathrm{~nm}$. All the release tests were performed at least in triplicate and the mean \pm SD was reported.

The release profiles were finally compared using the similarity factor $f_{2}$. The similarity factor is a logarithmic reciprocal square-root transformation of the sum of squared error and is a measurement of the closeness in percentage of dissolution between two release profiles, according to Eq. 3:

$f_{2}=50 * \log \left\{1+\left[\frac{1}{n} * \sum_{t=1}^{n}\left(R_{t}-T_{t}\right)^{2}\right]^{-0.5} * 100\right\}$

where $\mathrm{n}$ is the sampling number, $\mathrm{R}_{t}$ and $T_{t}$ are the cumulative percentage dissolved of the reference and the test products at each time point t. According to Moore and Flanner, ${ }^{21}$ two dissolution profiles are considered similar if the $f_{2}$ value is between 50 and 100 .

\subsection{Statistical analyses}

Statistical comparison among tensile properties was performed by ANOVA and Tukey-Kramer tests. Differences were considered significant when $p$-value were lower than 0.05 . 


\section{Results and discussion}

\subsection{Production and evaluation of the melatonin-loaded microparticles}

In the first part of the work, the production of solid lipid microparticles able to control the release of melatonin was investigated. Among the number of different lipidic carriers suitable for the preparation of microparticulate systems by spray congealing, tristearin and hydrogenated castor oil were selected due to their higher melting point. Table 1 reported the composition and the properties of the obtained microparticles. Considering that MP were intended to be incorporated in a film having a thickness lower than $100 \mu \mathrm{m}$, an important issue was related to their size; the fraction of interest was then established in the range $50-75 \mu \mathrm{m}$. The results showed that actual melatonin content was quite close (>80\%) to the theoretical one and the yield of the useful fraction was more influenced by the carrier rather than by the melatonin concentration (Table 1). The lower useful yield registered for hydrogenated castor oil was due to bigger size of microparticles.

In order to detect possible drug and/or carrier solid state modification after spray congealing process, the microparticles were analyzed by means of DSC. In particular, the raw materials, the physical mixture and the corresponding melatonin-loaded and placebo microparticles were compared (Figure 1a and 1b).

Figure 1a shows the data of melatonin and microparticles made of tristearin (Form. $\mathrm{MP}_{1}-\mathrm{MP}_{3}$ ). The DSC curve of the raw melatonin and tristearin (D) presented the characteristic endothermic peaks at $125^{\circ} \mathrm{C}$ and $79^{\circ} \mathrm{C}$, respectively and their physical mixture (PM) did not present any significant modification of the signals. On the contrary, the placebo microparticles $\left(\mathrm{MP}_{1}\right)$ showed a significant depression of melting peak, which shifted to $57^{\circ} \mathrm{C}$. This event was attributed to the presence of the $\alpha$ form of tristearin induced by the spray congealing; $\alpha$-form melting peak was followed by the exothermic peak of recrystallization into the stable $\beta$ form, before another endothermic peak due to the melting of $\beta$ form. This change of the original polymorphic form of tristearin due to the fast solidification from the melt during the spray congealing process is in agreement with previous data. ${ }^{22}$ However, the polymorphic modification of the carrier was not associated to any variation of the endothermic peak attributed to melatonin ( $\mathrm{MP}_{3}$, Figure 1a).

Figure $\mathbf{1 b}$ showed the results for hydrogenated castor oil systems: the DSC pattern of the carrier (C) evidenced a wide melting endotherm peak at $90^{\circ} \mathrm{C}$ with a shoulder at lower temperature. The corresponding thermogram of placebo $\left(\mathrm{MP}_{4}\right)$ was similar to that of raw hydrogenated castor oil, 
indicating that in this case the production process did not modify the solid state of the carrier. The DSC trace of melatonin loaded microparticles $\left(\mathrm{MP}_{6}\right)$ was superimposable to that of the physical mixture and showed an endothermic peak at $90^{\circ} \mathrm{C}$, due to the melting of the lipid, and a second endothermic peak at $120^{\circ} \mathrm{C}$, due to the melting of the melatonin.

The enthalpies values associated to the melting of melatonin were proportional to its relative abundance in the formulations independently of the carrier used (data not shown) suggesting that the manufacturing process did not affect their original solid state of the drug. To further elucidate the melatonin solid state in the solid lipid microparticles, physical changes in the samples on heating were monitored using hot stage microscopy. This analysis confirmed the presence of melatonin in the naïve crystalline state (Figure $\mathbf{2 a}$ and $\mathbf{2 b}$ ).
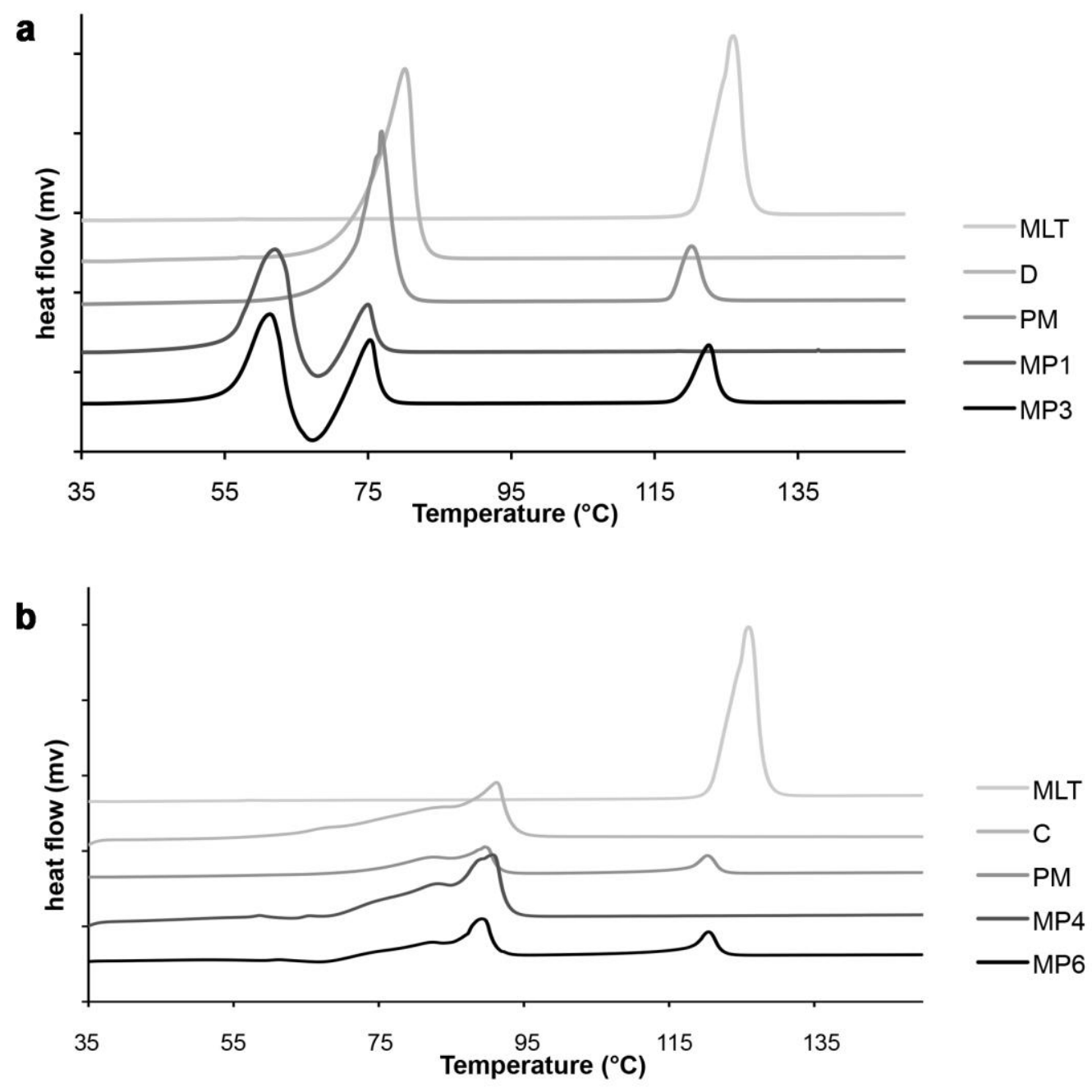

Figure 1 - DSC curves of the raw melatonin and lipid carriers, their physical mixtures (PM) and the corresponding placebo and melatonin-loaded microparticles. a) tristearin-systems and b) hydrogenated castor oil-systems. 

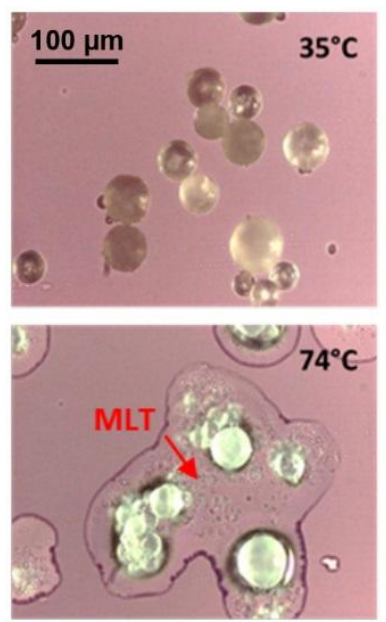

a

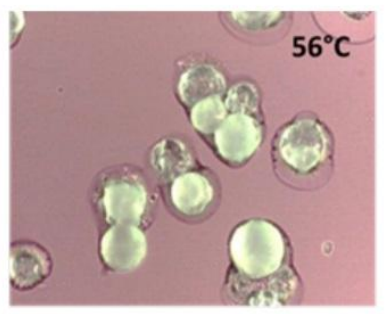

$121^{\circ} \mathrm{C}$
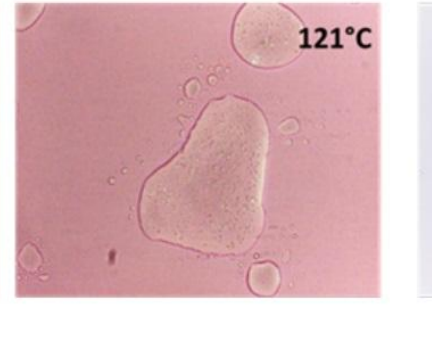
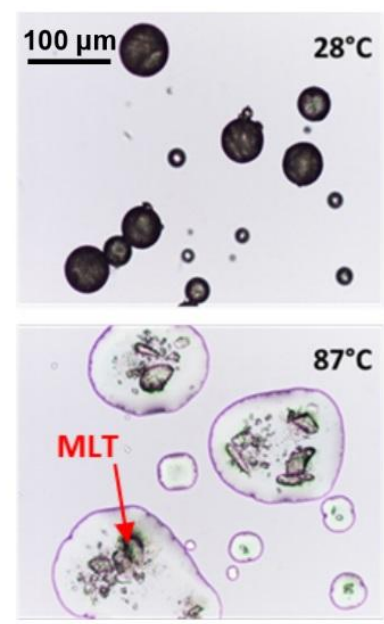

b

Figure 2 - Hot stage microscopy images of a) tristearin-based microparticles and b) hydrogenated castor oil microparticles (The magnification was at 10x).

Finally, in vitro dissolution tests of microparticles were performed to investigate their ability to control the melatonin release in both simulated gastric and intestinal conditions (Figure 3). Melatonin completely dissolved within $10 \mathrm{~min}$ in both dissolution media. As expected due to the nature of the selected excipients, the melatonin release was not influenced by the $\mathrm{pH}$ of the dissolution media. Indeed, the melatonin showed a sustained release profiles from the microparticles at both gastric and intestinal $\mathrm{pH}$. In particular, microparticles prepared by tristearin $\left(\mathrm{MP}_{2}\right.$ and $\mathrm{MP}_{3}$, Table 1) released more than $50 \%$ melatonin in 60 minutes at both $\mathrm{pH} 1.2$ and $\mathrm{pH}$ 6.8 (Figure $3 \mathbf{a}$ and $\mathbf{3 b}$ ) independently of the drug content $\left(f_{2}=93\right.$ at $p H 1.2$ and $f_{2}=72$ at $p H$ 6.8). Similar results were obtained for hydrogenated castor macroparticles (Figure $\mathbf{3 c}$ and $\mathbf{3 d}$ ): the melatonin release was not influenced neither by the drug content $\left(M P_{5}\right.$ vs $M P_{6}$ at $p H$ 1.2, $f_{2}=53$; $M P_{5}$ vs $M P_{6}$ at $\left.p H=6.8, f_{2}=52\right)$ nor by the $\mathrm{pH}$ of the media $\left(\mathrm{pH} 1.2 \mathrm{vs} \mathrm{pH} 6.8\right.$ for $\mathrm{MP}_{5}, f_{2}=67 ; \mathrm{pH} 1.2$ vs $\mathrm{pH} 6.8$ for $\mathrm{MP}_{6}, f_{2}=90$ ). In all cases, hydrogenated castor oil-based MP released only around $20 \%$ of MTL after $1 \mathrm{~h}$, confirming that the lipid microparticles produced by spray congealing were useful systems to sustain the melatonin release. 

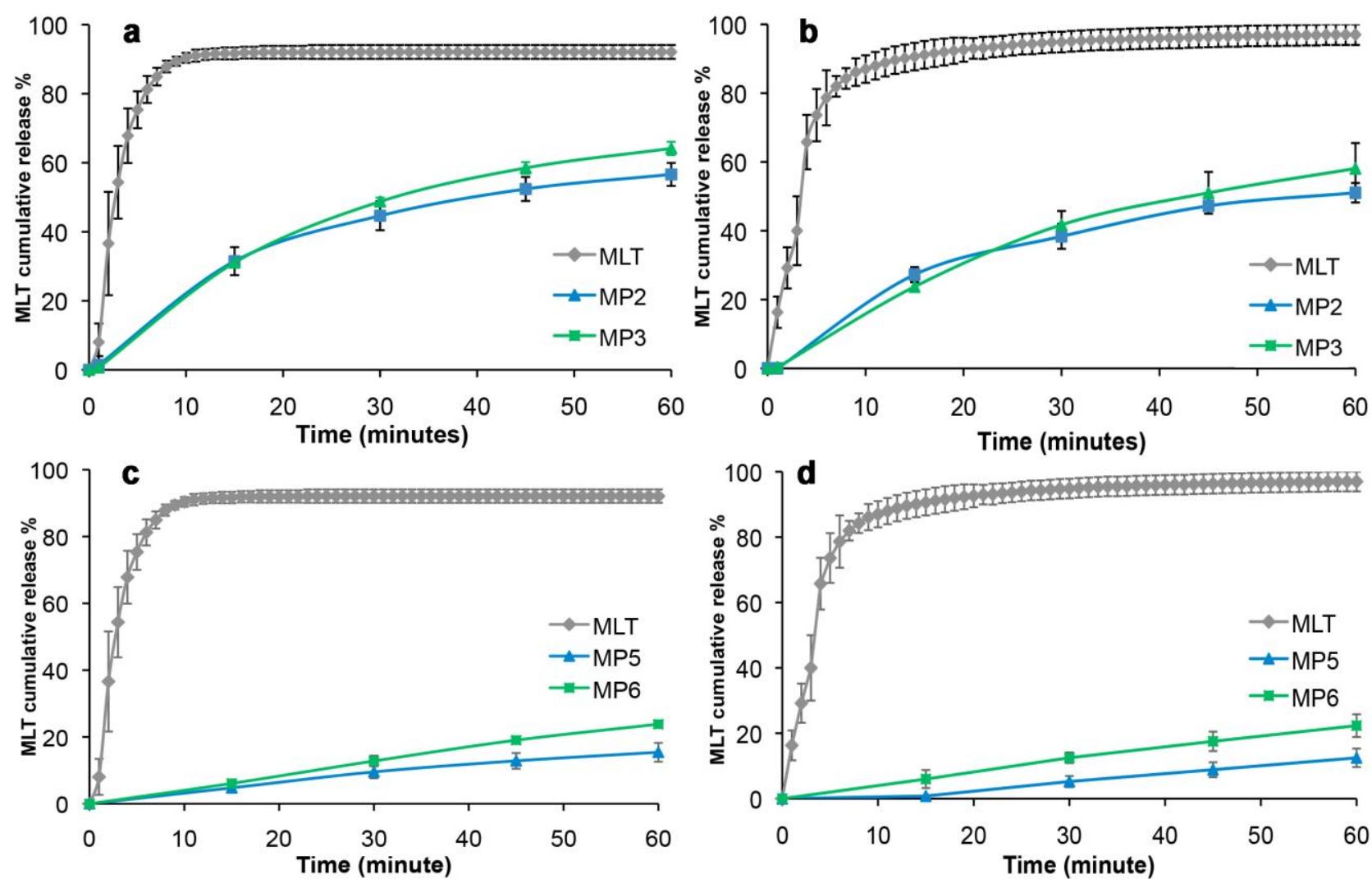

Figure 3 - Melatonin release profiles of tristearin-based microparticles $\left(\mathrm{MP}_{2}\right.$ and $\left.\mathrm{MP}_{3}\right)$ at $\mathrm{pH} 1.2$ (a) and $\mathrm{pH} 6.8$ (b) and of hydrogenated castor oil-based microparticles $\left(\mathrm{MP}_{5}\right.$ and $\left.M \mathrm{P}_{6}\right)$ at $\mathrm{pH} 1.2$ (c) and pH $6.8(d)$.

The results obtained in the first part of this research showed that the microparticles produced using hydrogenated castor oil as carrier had better performance in controlling the release of melatonin with respect to the tristearin ones. In addition, the MP made of tristearin started to melt just over $55^{\circ} \mathrm{C}$, due to the formation of the polymorphic form of the carrier. This fact could be a disadvantage for the ODFs preparation: the drying step is carried out at $60^{\circ} \mathrm{C}$, thus these microparticles could melt, altering their properties. Therefore, for the incorporation into the ODFs, the hydrogenated castor oil microparticles were selected.

\subsection{Film characterization}

\subsubsection{Morphology and mechanical properties}

The melatonin loading into the placebo formulation significantly decreased the $\sigma_{\max }(p<0.001)$ and $Y$ values $(p=0.0012)$ with respect to the placebo ODFs $\left(F_{1} v s F_{2}, F_{3} ;\right.$ Table 3$)$. In other words, melatonin impacted positively on the elasticity and negatively on strength of the maltodextrin- 
based ODF $\left(F_{1}\right)$. An opposite trend was observable for $\varepsilon$ values $(p<0.0001)$, which are generally related to the ductility of the film. These results suggested that melatonin acts as a plasticizer for maltodextrin-made matrices.

Table 3 - Technological performance of films loaded with microparticles and melatonin. Results are expressed as mean value \pm standard deviation $(n=5)$.

\begin{tabular}{cccccc}
\hline Formulation & $\begin{array}{c}\text { Thickness } \\
(\boldsymbol{\mu m})\end{array}$ & $\begin{array}{c}\mathbf{Y} \\
(\mathrm{MPa})\end{array}$ & $\begin{array}{c}\boldsymbol{\sigma}_{\max } \\
(\mathrm{MPa})\end{array}$ & $\begin{array}{c}\boldsymbol{\varepsilon} \\
(\%)\end{array}$ & $\begin{array}{c}\text { TEB } \\
(\mathbf{M P a})\end{array}$ \\
\hline$F_{1}$ & $111 \pm 5$ & $1.059 \pm 0.165$ & $1.265 \pm 0.077$ & $25.30 \pm 4.90$ & $0.171 \pm 0.026$ \\
$F_{2}$ & $110 \pm 12$ & $0.654 \pm 0.123$ & $1.091 \pm 0.083$ & $50.40 \pm 7.59$ & $0.307 \pm 0.038$ \\
$F_{3}$ & $128 \pm 2$ & $0.393 \pm 0.049$ & $0.653 \pm 0.065$ & $68.54 \pm 11.28$ & $0.151 \pm 0.017$ \\
$F_{6}$ & $196 \pm 5$ & $0.493 \pm 0.144$ & $0.932 \pm 0.111$ & $20.29 \pm 1.40$ & $0.136 \pm 0.010$ \\
$F_{8}$ & $157 \pm 6$ & $0.690 \pm 0.047$ & $1.011 \pm 0.100$ & $12.89 \pm 2.82$ & $0.095 \pm 0.030$ \\
$F_{9}$ & $235 \pm 5$ & $0.880 \pm 0.098$ & $0.569 \pm 0.099$ & $1.51 \pm 0.22$ & $0.003 \pm 0.001$ \\
\hline
\end{tabular}

When the MP were loaded up to $30 \% \mathrm{w} / \mathrm{w}$, an increase of the film thickness (Table 3 ) without altering the inner structure of MP. These findings were also confirmed by the comparison of particle distribution conducted before and after the loading in the film since no significant differences in terms of mean value and span were observed $(p>0.05)$. As expected, the particle count resulted in agreement with the theoretical weight content of MP (Table 4).

Table 4 - Particle area distribution of microparticles $\left(\mathrm{MP}_{4}\right)$ loaded in ODFs (mean value \pm dev.st). The $\mathrm{MP}_{4}$ data before drug loading was also reported as an example of the lack of modification of particle size distribution during the preparation of the ODF.

\begin{tabular}{cccccccc}
\hline Form. & $\begin{array}{c}\text { MP content } \\
\left(\mathrm{mg} / \mathrm{cm}^{2}\right)\end{array}$ & Particle count & $\begin{array}{c}\mathbf{d}_{10} \\
(\mu \mathrm{m})\end{array}$ & $\begin{array}{c}\mathbf{d}_{50} \\
(\mu \mathrm{m})\end{array}$ & $\begin{array}{c}\mathbf{d}_{90} \\
(\mu \mathrm{m})\end{array}$ & $\begin{array}{c}\text { Mean } \\
(\mu \mathrm{m})\end{array}$ & span \\
\hline $\mathrm{F}_{4}$ & 0.8 & $5114 \pm 112$ & $12.48 \pm 1.90$ & $59.41 \pm 4.53$ & $101.76 \pm 0.00$ & $59.92 \pm 0.37$ & $1.51 \pm 0.08$ \\
$\mathrm{~F}_{5}$ & 6.0 & $48836 \pm 654$ & $\begin{array}{c}16.26 \pm 0.8 \\
8\end{array}$ & $60.12 \pm 0.95$ & $86.33 \pm 0.38$ & $58.18 \pm 2.47$ & $1.17 \pm 0.04$ \\
$\mathrm{~F}_{6}$ & 6.0 & $56967 \pm 16206$ & $16.10 \pm 4.25$ & $55.93 \pm 7.74$ & $86.68 \pm 6.61$ & $54.96 \pm 6.93$ & $1.27 \pm 0.13$ \\
$\mathrm{MP}_{4}$ & - & $16638 \pm 2017$ & $15.36 \pm 0.05$ & $71.33 \pm 21.39$ & $90.77 \pm 20.41$ & $60.45 \pm 14.84$ & $1.06 \pm 0.03$ \\
$\mathrm{MP}_{5}$ & - & $18938 \pm 1236$ & $13.90 \pm 2.1$ & $62.53 \pm 19.69$ & $83.91 \pm 15.97$ & $55.54 \pm 14.71$ & $1.14 \pm 0.14$ \\
& & & 1 & & & & \\
\hline
\end{tabular}


Regarding the ODF tensile properties, also microparticles reduced the $\sigma_{\max }(p<0.01)$ and $Y$ values $(p<0.003)$ in comparison to the placebo formulation $\left(F_{6}\right.$ vs $F_{1}$; Table 3$)$; meanwhile no significant changes were observed in terms of ductility and tenacity of the MPs-loaded film $\left(F_{6} \vee F_{1}\right)$. On the contrary, the concomitant loading of melatonin and microparticles $\left(F_{8}, F_{9}\right)$ significantly decreased $\varepsilon$ and TEB with respect to microparticle free films $\left(F_{1}, F_{2}\right)$, evidencing a synergic and negative influence of melatonin and microparticles on the film fragility $(p<0.0001)$. These results seemed in contrast with the plasticizer effect of melatonin observed for microparticle-free ODF. However, it can be explained considering that the presence of solid material, such as microparticles, may alter the homogeneity of the ODF matrix and result in a weaker structure of the film from a mechanical point of view. This effect was already described of other ODF formulations ${ }^{23}$ the greater the amount of powder loaded in the film the greater the film fragility. Nevertheless, even if $\mathrm{F}_{8}, \mathrm{~F}_{9}$ are more fragile than other formulation, its tensile properties resulted in the range of agreed with those already available on the market. ${ }^{24}$

SEM images showed that all ODFs had a regular and smooth surface (Figure 4a). The cross-section of the films containing microparticles $\left(F_{4}, F_{6}\right.$ and $\left.F_{9}\right)$ evidenced that the MP were homogeneously distributed into the films, maintaining their spherical shape. These results confirmed that the microparticles were successfully incorporated into the films. In addition, melatonin crystals are appreciable in both film surface and particle section of the $F_{3}$ and $F_{9}$ ODFs. 

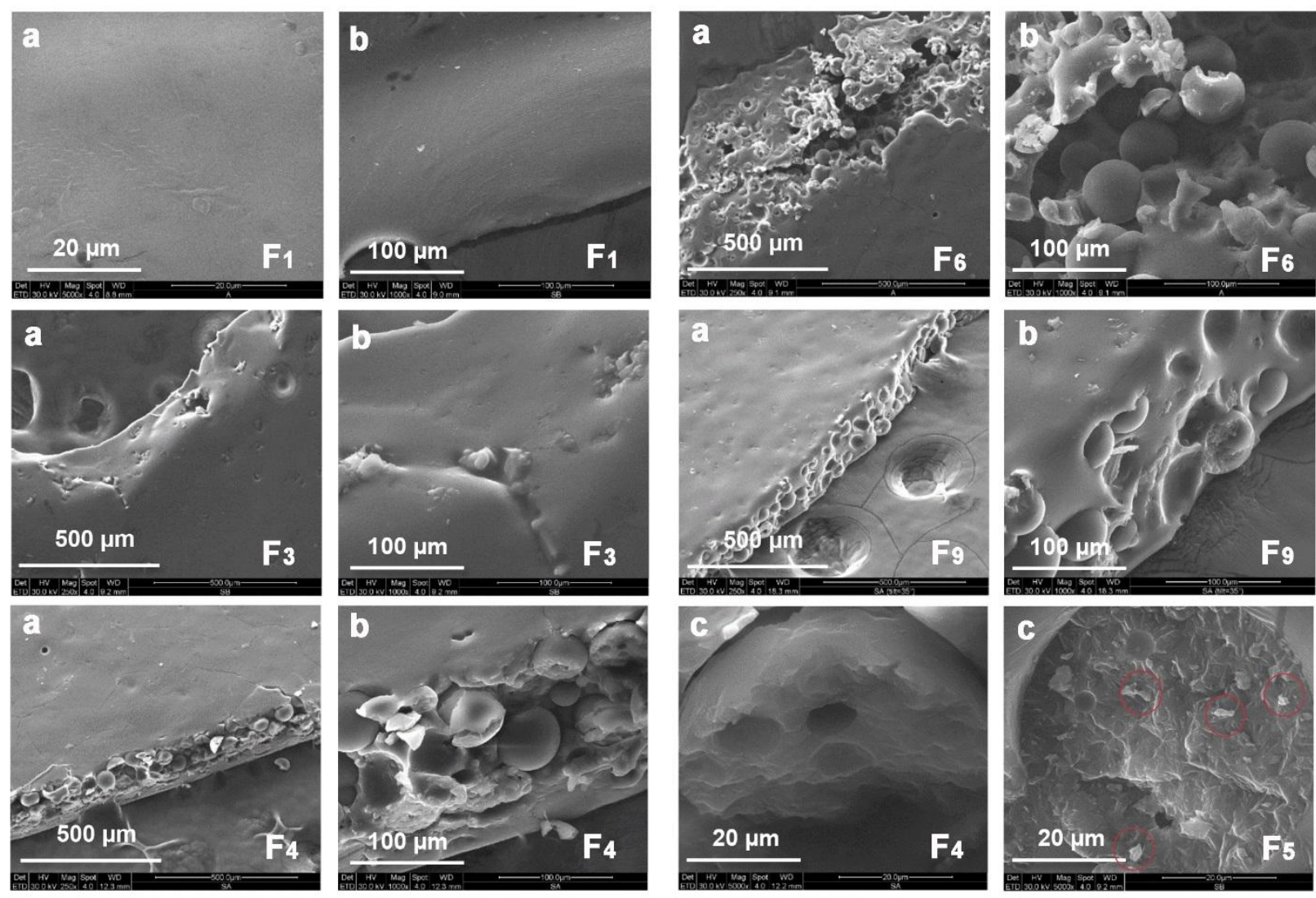

Figure 4 - SEM images at different magnification ( $a$ : is 250X, b: is 1000X and $c$ : is 5000X) of ODFs: placebo $\left(F_{1}\right)$, melatonin loaded $\left(F_{3}\right)$, microparticle loaded $\left(F_{4}\right)$, microparticle-containing-melatonin loaded $\left(F_{6}\right)$, and melatonin and microparticle-containing-melatonin loaded $\left(F_{9}\right)$.

\subsubsection{Thermal analysis}

ODFs were also caracterized in terms of thermal properties by DSC analysis. The DSC curve of Form. $F_{1}$ (Figure 5) showed only a wide endothermic peak between 60 and $95^{\circ} \mathrm{C}$, presumably due to the process of evaporation of the water contained in the film. The Form. $F_{3}$, containing free melatonin, displayed a DSC curve with a less intense endothermic peak and slightly shifted to lower temperatures associated with melatoinin melting. The DSC curves of Form. $F_{7}$ and $F_{9}$ present both the endothermic peaks characteristic of the excipient $\left(90^{\circ} \mathrm{C}\right)$ and melatonin $\left(126^{\circ} \mathrm{C}\right)$. In particular, the endothermic peak of lipid carrier in Form. $F_{9}$ is clearly displayed while the peak of the melatonin is hardly visible: only slight variation of the base line can be seen at lower temperatures (between 95 and $105^{\circ} \mathrm{C}$ ) attributable to melatonin, probably due to dilution with the 
excipients of the film. Differently, in Form. $F_{9}$, the melatonin endothermick peak was more appreciable and shifted to higher values (between 105 and $120{ }^{\circ} \mathrm{C}$ ), due to the melting of melatonin crystals dispersed into the film matrix. On the basis of this results it is possible to hypothesize that no interactions between the drug-loaded microparticles and the matrix of ODFs occured.

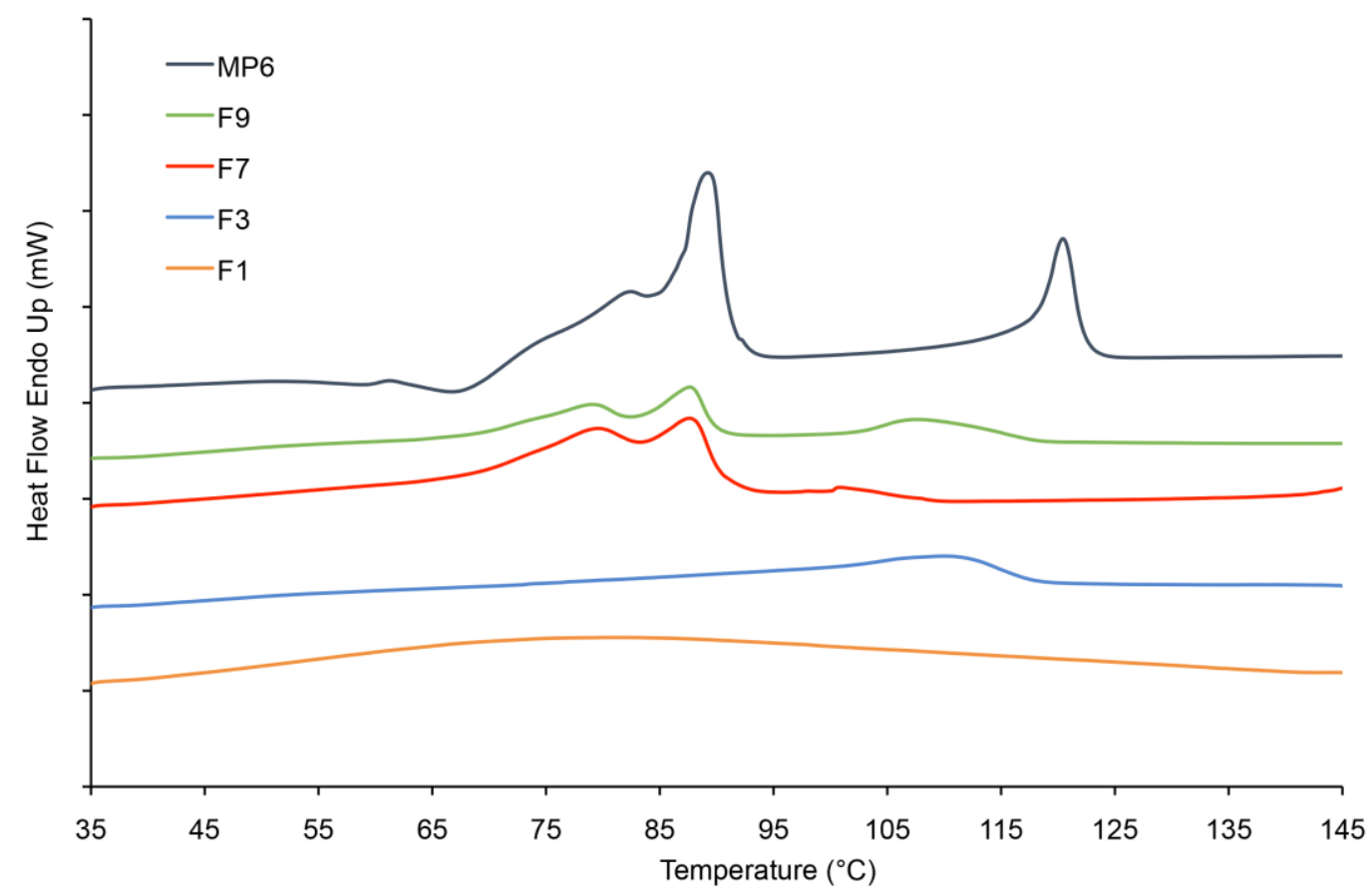

Figure 5 - Typical DSC curves of melatonin-loaded microparticles $\left(M P_{6}\right)$, placebo ODF $\left(F_{1}\right)$, melatonin-loaded $\operatorname{ODF}\left(F_{3}\right)$, microparticle-containing-melatonin loaded ODF $\left(F_{7}\right)$, melatonin and microparticle-containing-melatonin loaded ODF $\left(F_{g}\right)$.

\subsubsection{Melatonin release studies}

The last part of the research was the evaluation of melatonin release in different media from the ODFs. Furthermore, ODFs containing the empty microparticles $\left(F_{4}\right)$ were analyzed to evaluate possible interferences given by the components of the film.

As expected, ODFs containing free melatonin $\left(F_{2}\right.$ and $F_{3}$, containing $2.5 \%$ and $6 \%$ melatonin, respectively), showed a rapid dissolution of the drug both in Simulated Salivary Fluid (Figure 6a) 
and Simulated Gastric Fluid (Figure 6b). The melatonin dissolved within 30 min, regardless its content in the ODFs.
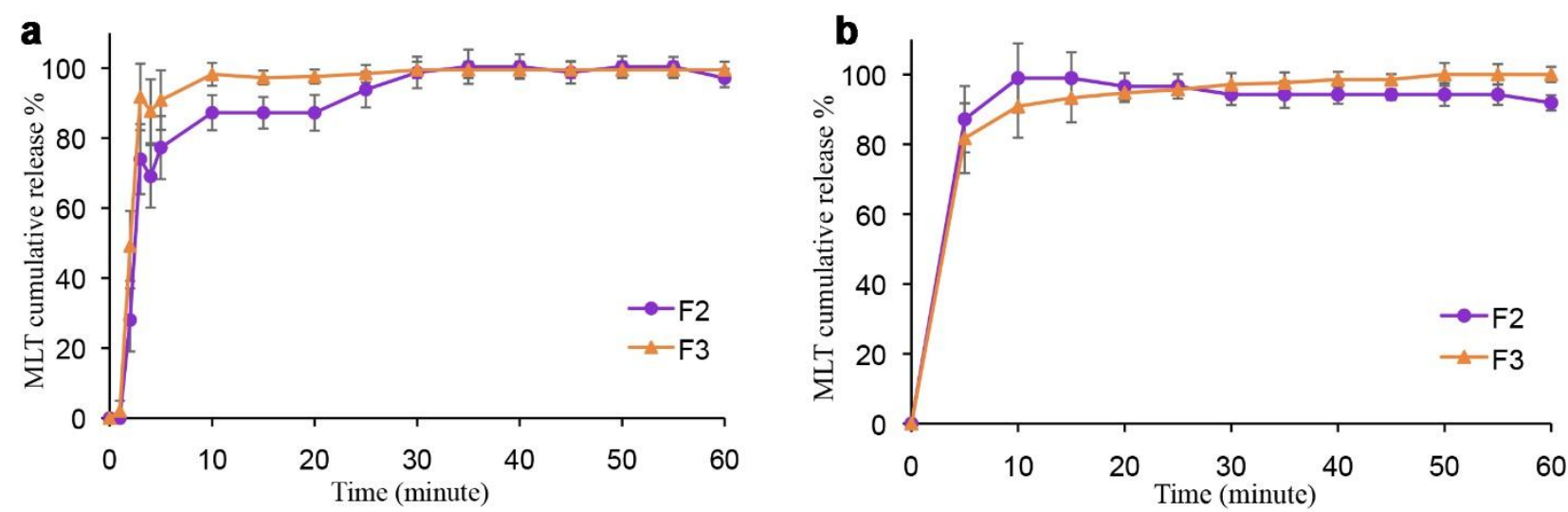

Figure 6-Dissolution profiles of $F_{2}$ e $F_{3}$ ODFs: (a) in simulated salivary fluid; (b) in simulated gastric

fluid.

The release studies of ODFs containing microparticles $\left(F_{6}\right.$ and $\left.F_{7}\right)$ and the films containing both free and melatonin-loaded microparticles $\left(F_{8}\right.$ and $\left.F_{9}\right)$ were performed. The Figure $7 a$ shows the melatonin release pattern in Simulated Salivary Fluid over an $1 \mathrm{~h}$ period. The Figure $\mathbf{7 b}$ shows the drug release after exposition of the formulation to Simulated Salivary Fluid for 5 minutes to mimic the oral cavity, then Simulated Gastric Fluid for 1 hour to estimate the release in the stomac and, finally in Simulated Intestinal Fluid for 4 hours.

As desired, the release of melatonin from the systems containing encapsulated drug $\left(F_{5}\right.$ and $\left.F_{6}\right)$ was significantively lower respect to $F_{2}$ and $F_{3}$ films (compare Figure $7 a$ with Figure 6a). The amount of melatonin released from $\mathrm{F}_{6}$ and $\mathrm{F}_{7}$ was lower than $20 \%$ after 10 minutes in saliva. Indeed, even if the incorporation of the microparticles into the ODFs enhanced the release of melatoninin comparison to "free" microparticles (compare with Figure $\mathbf{3 c}$ and $\mathbf{3 d}$ ), the microparticle was slowly released from $\mathrm{F}_{6}$ and $\mathrm{F}_{7}$, reaching the $35 \%$ and $60 \%$ after 1 hour in SGF and $50 \%$ and $80 \%$, after 5 hours, respectively (Figure $\mathbf{7 b}$ ). The enhanced drug release from microparticles after incorporation in ODFs was previously observed by Brniak et al. ${ }^{25}$ and could be explained by the faster wetting of the microparticles while dispersed in the solubility enhancing agents, which formed the films (maltodextrins).

Finally, the release behavior of films containing both free melatonin and melatonin-loaded microparticles at different loading $\left(\mathrm{F}_{8}\right.$ and $\left.\mathrm{F}_{9}\right)$ was consistent with their composition: in simulated salivary fluid, the amount of melatonin released was intermediate respect to melatinin-loaded 
films and microparticle-loaded ones (Figure 7a). In simulated gastric fluid most of the melatonin was dissolved reaching about the $70 \%$ and $90 \%$ of drug released, while in simulated intestinal fluid the drug release from microparticles proceeded in a controlled manner (Figure 7b). The best performance was thus achieved by $\mathrm{F}_{6}$ system: ODFs containing melatonin-loaded-microparticles allowed a sustain the drug release for at least 5 hours.

a

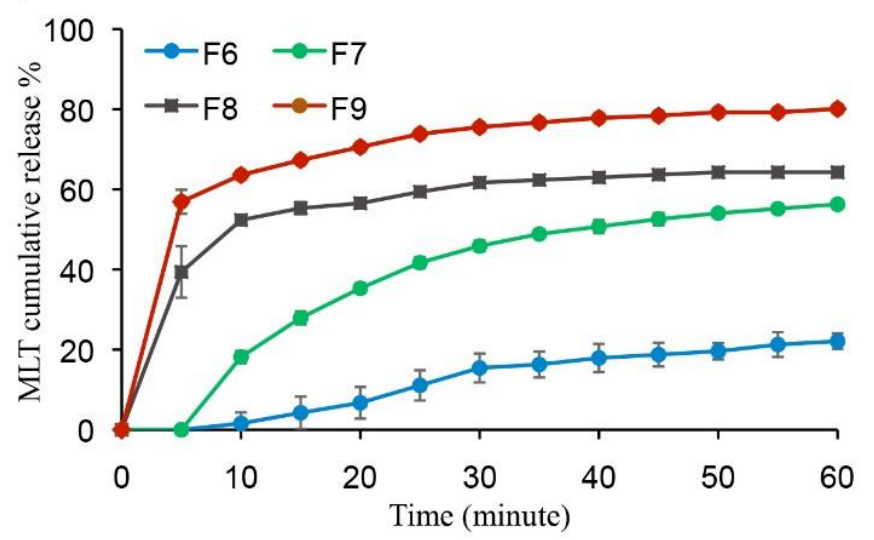

b

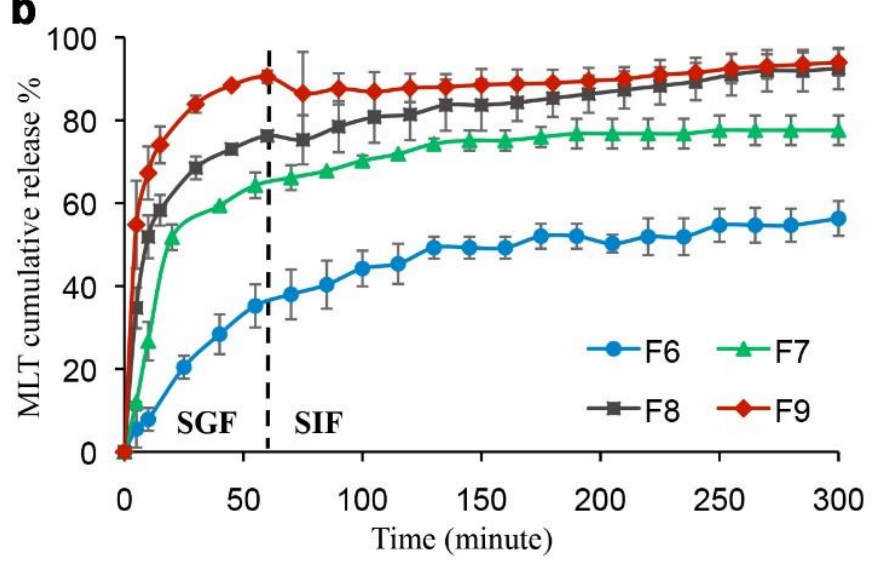

Figure 7 - Release profiles of melatonin from $F_{6}, F_{7}, F_{8}$ and $F_{9}$ ODFs: (a) in simulated salivary fluid (SSF); (b) changing the composition and pH over 5 hours [5 min in SSF + 1h in simulated gastric fluid (SGF) +4 in simulated intestinal fluid (SIF)]. 


\section{Conclusions}

The overall results demonstrated that ODFs made of maltodextrin can be a suitable technological platform for loading lipid microparticles without altering significantly both the shape and dimension of the microparticles and the mechanical properties of the films. Indeed, although the observed differences in tensile parameters among the formulations, the results agree with published data obtained on commercially-available ODFs.

Thanks to the incorporation of drug-loaded hydrogenated castor oil into the ODFs, the platform permits to modulate the melatonin release: the amount of drug dissolved in the stomach could decrease the sleep onset latency, while the sustained drug release for 5 hours could increase the total sleep time. In addition, the innovative delivery system maintains the advantages of ODFs, thus is suitable for the melatonin administration to patients, such as pediatric and geriatric populations, with swallowing difficulties. 


\section{References}

1 Haus, E., 2007. Chronobiology in the endocrine system. Advanced Drug Delivery Reviews 59, 985-1014.

2 Bruni, O., Alonso-Alconada, D., Besag, F., Biran, V., Braam, W., Cortese, S., Moavero, R., Parisi, P., Smits, M., Van der Heijden, K., Curatolo, P., 2015. Current role of melatonin in pediatric neurology: clinical recommendations. Eur J Paediatr Neurol, 19 (2), 122-133.

3 Jain, S.V., Horn, P.S., Simakajornboon, N., Beebe, D.W., Holland, K., Byars, A.W., Glauser, T.A., 2015. Melatonin improves sleep in children with epilepsy: a randomized, double-blind, crossover study. Sleep Med 16(5), 637-44.

4 Tsai, M.H., Hsu, J.F., Huang, Y.S., 2016. Sleep Problems in Children with Attention Deficit/Hyperactivity Disorder: Current Status of Knowledge and Appropriate Management. Curr Psychiatry Rep 18(8), 76.

5 Brzezinski, A., Vangel, M.G., Wurtman, R.J., Norrie, G., Zhdanova, I., Ben-Shushan, A., Ford, I., 2005. Effect of exogenous melatonin on sleep: a meta-analysis. Sleep Med Rev 9, 41-50.

6 EMA. European Medicines Agency decision P/0117/2012 (EMA/405270/2010). Available on line at: http://www.ema.europa.eu/docs/en_GB/document_library/EPAR__Summary_for_the_public/human/000695/WC500026805.pdf.

7 Chua, H.M, Hauet Richer, N., Swedrowska, M., Ingham, S., Tomlin, S., Forbes, B., 2016.

Dissolution of Intact, Divided and Crushed Circadin Tablets: Prolonged vs. Immediate Release of Melatonin. Pharmaceutics, 8(1), 2.

8 Albertini, B., Di Sabatino, M., Melegari, C., Passerini, N., 2014. Formulating SLMs as oral pulsatile system for potential delivery of melatonin to pediatric population. Int J Pharm, 469, 67-79.

9 Vlachou, M., Papamichael, M., Siamidi, A., Fragouli, I., Afroudakis, P.A., Kompogennitaki, R., Dotsikas, Y., 2017. Comparative In Vitro Controlled Release Studies on the Chronobiotic Hormone Melatonin from Cyclodextrins-Containing Matrices and Cyclodextrin: Melatonin Complexes. Int J Mol Sci, 18(8), 1641.

10 Cilurzo, F., Musazzi, U.M., Franzè, S., Selmin, F., Minghetti, P., 2018. Orodispersible dosage forms: biopharmaceutical improvements and regulatory requirements. Drug Discov. Today, 23, 251-259. 
11 Hoffmann, E.M., Breitenbach, A., Breitkreutz, J., 2011. Advances in orodispersible films for drug delivery. Expert Opin. Drug Deliv. 8(3), 299-316.

12 Orlu, M., Ranmal, S. R., Sheng, Y., Tuleu, C., Seddon, P., 2017. Acceptability of orodispersible films for delivery of medicines to infants and preschool children. Drug Deliv. 24, 1243-1248.

13 Preis, M.,2015. Orally disintegrating Film and minitablets-Innovative dosage forms of choice for pediatric use. AAPS PharmSciTech 16, 234-241.

${ }^{14}$ Speer, I., Preis, M., Breitkreutz, J., 2018. Prolonged drug release properties for orodispersible films by combining hot-melt extrusion and solvent casting methods. Eur J Pharm Biopharm. 129, 66-73.

${ }^{15}$ Speer, I., Lenhart, V., Preis, M., Breitkreutz, J., 2019. Prolonged release from orodispersible films by incorporation of diclofenac-loaded micropellets. Int J Pharm, 554, 149-160.

${ }^{16}$ Scalia, S., Young, P.M., Traini, D., 2015. Solid lipid microparticles as an approach to drug delivery, Expert Opin Drug Deliv. 12, 583-599.

${ }^{17}$ Passerini, N, Albertini, B., Di Sabatino, M., Corace, G., Luppi, B., Canistro, D., Vivarelli, F., Cirillo, S., Soleti, A., Merizzi, G., Paolini, M., 2016. Development of microparticles for oral administration of the non-conventional radical scavenger IAC and testing in an inflammatory rat model. Int J Pharm., 512, 126-136

${ }^{18}$ Cilurzo L., Cupone I.E. , Minghetti P., Selmin F., Montanari L. Fast dissolving films made of maltodextrins (2008) Eur. J. Pharm. Biopharm., 70 (3): 895-900

${ }^{19}$ Cilurzo F., Cupone I.E., Minghetti P., Buratti S., Selmin F., Gennari C.G.M., Montanari L. 2010. Nicotine fast dissolving films made of maltodextrins: a feasibility study. AAPS Pharm Sci Tech, 11 (4), 1511-1517.

${ }^{20}$ Franceschini, I., Selmin, F., Pagani, S., Minghetti, P., Cilurzo F., 2016. Nanofiller for the mechanical reinforcement of maltodextrins orodispersible films. Carbohydrate Polymers, 136, 676-681.

21 Moore, J.V., Flanner, H.H., 1996. Mathematical Comparison of Dissolution Profiles. Pharm Technol, 20(6), 64-74.

22 Di Sabatino, M., Albertini, B., Kett, V.L., Passerini, N., 2012. Spray congealed lipid microparticles with high protein loading: Preparation and solid state characterization. Eur J Pharm Sci, 46, 346356.

${ }^{23}$ Musazzi, U.M., Selmin, F., Franzè, S., Gennari, C.G.M., Rocco, P., Minghetti, P. Cilurzo, F., 2018. Poly(methyl methacrylate) salt as film forming material to design orodispersible films. Eur. J. Pharm. Sci., 115, 37-42. 
24 Borges, A.F., Silva, C., Coelho, J.F.J., Simoes, S., 2016. Outlining critical quality attributes (CQAs) as guidance for the development of orodispersibile films. Pharm Dev Technol, 22(2), 237-245.

${ }^{25}$ Brniak, W., Maslak, E., Jachowicz, R., 2015. Orodispersible films and tablets with prednisolone microparticle. Eur J Pharm Sci 75, 81-90. 